\title{
REVOLUSI YANG DITANGGUHKAN KARYA SHAHNON AHMAD BERDASARKAN PERSPEKTIF TAKMILAH
}

\section{(A Look at Shahnon Ahmad's Revolusi yang Ditangguhkan from the Takmilah Perspective)}

Kamariah Kamarudin

kkamaria@upm.edu.my

Jabatan Bahasa Melayu,

Fakulti Bahasa Moden dan Komunikasi,

Universiti Putra Malaysia,

43400 Serdang, Selangor, Malaysia.

\begin{abstract}
Abstrak
Kajian ini meneliti karya semi ilmiah Shahnon Ahmad, Revolusi Yang Ditangguhkan (2011) berdasarkan perspektif teori takmilah. Kajian ini merungkai sejauh mana tujuh prinsip takmilah yang digagaskan Shafie Abu Bakar, iaitu (1) prinsip ketuhanan yang bersifat kamal (sempurna), (2) prinsip kerasulan sebagai insan kamil (sempurna), (3) prinsip keislaman yang bersifat yang bersifat akmal (sempurna), (4) prinsip ilmu dengan sastera yang bersifat takmilah (sempurna), (5) prinsip sastera sendiri yang berciri estetik dan bersifat takmilah (sempurna dan menyempurnakan), 6) prinsip pada pengkarya yang seharusnya mengistikmalkan diri (menyempurnakan) dan (7) prinsip khalayak bertujuan memupuk mereka ke arah insan kamil (sempurna) diajukan pengarang dalam karyanya. Kajian ini memperlihatkan peri pentingnya hubungan karya-pengkarya-khalayak dalam menyampaikan perutusan yang bermanfaat kepada masyarakat demi kemaslahatan ummah jagat raya.
\end{abstract}

Kata kunci: Revolusi yang Ditangguhkan, Shahnon Ahmad, perspektif takmilah 


\begin{abstract}
This study looks at Shahnon Ahmad's Revolusi Yang Ditangguhkan (2011) using the perspective of the takmilah theory. The study aims to uncover the extent to which the writer, in this work, observes the seven principles of takmilah outlined by Shafie Abu Bakar: (1) the principle of godliness as being kamal (perfect), (2) the principle of prophethood as a kamil (perfect) creation, (3) the principle that Islam is akmal (more perfect), (4) the principle of knowledge and literature as being takmilah (perfected), (5) the principle of literature itself as being aesthetic in nature as well as takmilah (perfect and perfecting), (6) the principle that the writer should continually practice istikmal (perfecting) of the self, and (7) the principle that readers should be encouraged to aim for becoming insan kamil (perfect beings). This study reveals the importance of the work-writer-audience relationship in conveying a message to society that is beneficial, for the betterment of the universal ummah.
\end{abstract}

Keywords: Revolusi yang Ditangguhkan, Shahnon Ahmad, takmilah perspective

\title{
PENDAHULUAN
}

Perkembangan persuratan Melayu memperlihatkan kemunculan karya baharu saban tahun di pasaran. Kecenderungan ini bukan sahaja melibatkan karya kreatif, bahkan juga karya ilmiah dan semi ilmiah. Fenomena ini menarik perhatian pengkaji sastera kerana dalam konteks ilmiah, peri pentingnya kritikan dilakukan terhadap karya yang muncul untuk diperhatikan sejauh mana perkembangannya memberikan impak terhadap masyarakat. Khususnya karya Sasterawan Negara yang dinobatkan sebagai tokoh besar dalam perkembangan persuratan Melayu dan industri penerbitan buku negara dalam menampilkan hasil yang bersifat kemanusiaan dan Islamik.

Dalam perkembangan dunia kritikan sastera juga memperlihatkan kemunculan pendekatan dan teori tempatan yang bersesuaian untuk diaplikasikan dengan perkembangan karya yang pesat tersebut. Misalnya teori takmilah yang digagaskan oleh Shafie Abu Bakar yang meletakkan pendekatan hubungan yang erat antara karya-pengkarya-khalayak bersesuaian dijadikan sandaran dalam merungkai karya berunsur Islam dan rohani. Teori takmilah yang dibangunkan pada tahun 1992 ini bukan sekadar menjadikan tauhid sebagai asas perbincangan utama bahkan memperlihatkan kesatuan yang padu antara karya-pengkarya-khalayak dalam menggariskan konsep habl min Allah (hubungan manusia dengan Allah) dan habl min al-Nas (hubungan manusia dengan manusia). ${ }^{1}$ Gagasan yang dijana oleh mantan 
pensyarah Universiti Kebangsaan Malaysia (UKM) ini dilihat sejajar dengan perungkaian terhadap karya yang bersifat kemanusiaan dan Islamik. Malahan teori takmilah juga dilihat sebagai teori yang bukan sekadar merungkai karya sastera yang bersifat kreatif bahkan dapat diaplikasikan dalam bentuk Persuratan Adab dan Tamadun yang diringkaskan sebagai PESURAT yang memperihalkan tentang semua yang tersurat bahkan tersirat yang bersifat ilmu dan bersifat kreatif. ${ }^{2}$ Oleh yang demikian, kajian ini meneliti buku semi ilmiah Shahnon Ahmad, Revolusi yang Ditangguhkan berdasarkan perspektif takmilah.

\section{SHAHNON AHMAD DAN REVOLUSI YANG DITANGGUHKAN}

Shahnon Ahmad yang mula berkarya sejak tahun 1960-an merupakan antara penulis prolifik tanah air. Bermula dengan novel pertama, Rentong (1965) dan terkini dengan novel Mahhabah (2000), Shahnon banyak mendapat pengiktirafan dalam dunia penulisan. Bahkan beliau merupakan antara Sasterawan Negara Malaysia yang boleh berkarya dalam penulisan kreatif dan ilmiah. Kecenderungan ini memperlihatkan keistimewaannya sebagai seorang tokoh Sasterawan Negara lantaran tulisannya mempunyai bauran ilmiah + kreatif, dan kreatif + ilmiah untuk dihadamkan oleh masyarakat.

Selain aktif menulis puluhan novel dan ratusan cerpen dalam bidang karya kreatif, Shahnon juga terkenal dalam penghasilan tulisan ilmiah sejajar dengan pelibatannya sebagai pensyarah di kampus Minden. Walaupun terkenal juga sebagai seorang pengarang kreatif yang membawa isu kontroversi dalam puluhan novelnya, pun sumbangannya dalam dunia tulisan ilmiah amat bermakna dalam perkembangan sastera tanah air. Polemik sastera Islam antara beliau dengan Kassim Ahmad misalnya antara sumbangan Shahnon dalam memperkasakan perkembangan persuratan Melayu tanah air khususnya dalam usaha membuka jendela fikir penggiat sastera untuk memugar dunia kritikan sastera.

Antara buku ilmiahnya yang menguak horizon pembaca termasuklah Penglibatan dalam Puisi (Utusan Melayu Publication, 1978), Gubahan Novel (Dewan Bahasa dan Pustaka, 1979), Kesusasteraan \& Etika Islam (Fajar Bakti, 1981), Polemik Sastera Islam (Dewan Bahasa dan Pustaka, 1987), Seni Sastera Sebagai Seismograf Kehidupan (Dewan Bahasa dan Pustaka, 1991), Kesasterawanan: Kepolitikan, Kealaman, Kedirian, Kemanusiaan (Dewan Bahasa dan Pustaka, 1992), Pongang Sastera (Fajar Bakti, 1993), Corat-corat Berkelongsong (Fajar Bakti, 1995) dan Sastera: Pengalaman, 
Ilmu, Imaginasi dan Kitarannya (Dewan Bahasa dan Pustaka, 1994). Buku mutakhirnya ialah Revolusi yang Ditangguhkan (Alaf 21 Sdn. Bhd, 2011).

Dalam dunia akademik pula, beliau pernah memegang jawatan sebagai pensyarah, timbalan dekan (1976-1978), dekan (1978-1982) di Pusat Pengajian Ilmu Kemanusiaan, Universiti Sains Malaysia dan pengarah Pusat Islam (1984-1986) ${ }^{3}$ di universiti yang sama. Pelibatan akademik merupakan pengalaman luar biasa Shahnon sebagai pengarang kreatif dan pengarang ilmiah. Malahan, ratusan tulisan esei dan kritikannya dalam buku, majalah dan akhbar memperlihatkan sumbangan besar Shahnon Ahmad dalam dunia persuratan Melayu sebagai tokoh Sasterawan Negara. Kesungguhannya berkarya sejak tahun 1950-an sehingga kini dan tulisan dalam majalah Dewan Sastera dalam ruangan "Pabila Hujan Turun" memperlihatkan kegigihan Shahnon sebagai pengarang yang tekun walau dihadap dengan masalah kesihatan.

Sasterawan Negara ini juga bukan sekadar menyumbang dalam dunia penulisan, bahkan berperanan dalam menyemarakkan dunia kritikan sastera. Ketokohannya dalam bidang penulisan dapat pula menggalakkan penggiat dan sarjana sastera menulis tentang diri dan kritikan terhadap penulisannya. Situasi ini dapat diperhatikan menerusi puluhan buku ilmiah tentang Shahnon antaranya termasuklah "Kajian dan Pembicaraan Novel Rentong" (Dinas, 1972), Antara Kampung dan Kota Rural Bias in the Novels of Shahnon Ahmad (Ungku Maimunah Mohd. Tahir, UKM, 1998), Teknik Naratif Cerpen-cerpen Shahnon Ahmad (Talib Samat, UPSI, 2006), dan lain-lain. Di samping itu, kajian tentang karya Shahnon Ahmad juga diteliti pada peringkat Ijazah Doktor Falsafah, Sarjana Sastera dan Sarjana Muda Sastera. Antara kajian tentang penulisan Shah termasuklah "Mobiliti Sosial Perspektif Barat dan Islam dalam Novel-novel Terpilih Shahnon Ahmad" (Latihan Ilmiah, Pusat Pengajian Ilmu Kemanusiaan, USM, P.Pinang, 1990/91), "Bahasa Daerah dalam Karya-karya Shahnon Ahmad" (Mohd. Yusof Hasan, Tesis M. A. Pusat Pengajian ilmu Kemanusiaan, USM, P.Pinang, 1975/76), "Novel-novel Mutakhir Shahnon Ahmad (1980-an-1990-an): Satu Kajian Perhubungan Gender" (Ooi Eng Lye, Tesis M. A., Pusat Pengajian Ilmu Kemanusiaan, USM, P. Pinang, 1996), "Strategi Naratif dalam Fiksyen Shahnon Ahmad" (Talib Samat, Tesis PhD, Pusat Pengajian Ilmu Kemanusiaan, USM, P. Pinang, 1999).

Revolusi yang Ditangguhkan merupakan antara karya Shahnon yang terbaharu setelah bergelut dengan penyakit yang diharunginya sejak menempah usia warga emas. Buku yang diterbitkan oleh Alaf 21 Sdn. Bhd pada tahun 
2011 ini mengungkapkan pandangan dan kritikan Shahnon terhadap aspek sosial dan lingkaran kehidupan untuk manusia kembali kepada pengabdian Tuhan. Buku ini mengemukakan peringatan untuk manusia bermuhasabah memperbaik diri dengan pergelutan kehidupan yang sarat dengan cabaran. Buku ini mengandungi 11 tajuk dan kandungannya ialah "Bisikan Kalbu" (hlm. 7-12), "Prolog" (hlm. 13-24), "Pemberian" (25-70), "Penolakan" (71-100), "Penerimaan" (hlm. 101-26), "Kedurjanaan" (hlm. 127-46), "Kebiadaban" (hlm. 147-66), "Keigauan" (hlm. 167-92), "Revolusi" (hlm. 193-228), "Epilog" (hlm. 229-31) dan "Hanya DIA yang Tahu" (hlm. 23238). Berdasarkan penelitian, buku ini menjadi motivasi kepada pengarang muda tanah air, dan inspirasi kepada masyarakat amnya lantaran Shahnon bertarung dengan penyakit ganjilnya, myasthenia gravis ketika menyudahkan garapan penulisannya ini. Selain buku ini juga menyingkap pengalaman peribadi Shahnon sebagai seorang pejuang sastera tulen yang tetap berkarya untuk berbakti pada masyarakat walau diserang dengan penderitaan dan kesakitan yang menganggu proses fikiran dan kehidupannya.

Justeru, setelah melalui tahap-tahap dalam penulisan (karya), bermula daripada isu sosial kepada nilai keislaman, malahan peringkat peribadi pengarang, iaitu muhasabah diri daripada sihat kepada sakit (pengkarya), telah membawa kepada bauran emosi masyarakat (khalayak pembaca), maka kajian ini merungkai Revolusi yang Ditangguhkan berdasarkan perspektif takmilah yang menyarankan manusia menuju kepada kesempurnaan dalam kehidupan.

\section{REVOLUSI YANG DITANGGUHKAN BERDASARKAN PERSPEKTIF TAKMILAH}

Secara umumnya, teori takmilah menggariskan tujuh prinsip yang kesemuanya saling lengkap melengkapi untuk menuju kesempurnaan (takmilah). Oleh yang demikian, berdasarkan tujuh prinsip, iaitu prinsip ketuhanan yang bersifat kamal (sempurna), prinsip kerasulan sebagai insan kamil (sempurna), prinsip keislaman yang bersifat akmal (sempurna), prinsip ilmu dengan sastera yang bersifat takmilah (sempurna), prinsip sastera sendiri yang berciri estetik dan bersifat takmilah (sempurna dan menyempurnakan), prinsip pada pengkarya yang seharusnya mengistikmalkan diri (menyempurnakan), prinsip khalayak bertujuan memupuk mereka ke arah insan kamil (sempurna). 


\section{Prinsip Ketuhanan yang Bersifat Kamal (Sempurna)}

Berdasarkan prinsip pertama yang digariskan dalam teori takmilah ini, pengarang memperlihatkan keagungan Yang Maha Pencipta bagi alam semesta ini. Revolusi yang Ditangguhkan mengungkapkan peri pentingnya manusia mengakui kehebatan Allah SWT sebagai Maha Pencipta dan Maha Berkuasa yang mengatur kehidupan di dunia. Allah SWT yang bersifat kamal (sempurna) ini sewajarnya diyakini oleh setiap umat Islam lantaran menerusi al-Quran digagaskan kekuasaannya menerusi Surah al-Kahfi, Ayat $45 .{ }^{4} \mathrm{Hal}$ ini disuguhkan oleh pengarang berdasarkan kutipan berikut:

ALLAH Maha Kuasa atas segala sesuatu (18:45). Tapi sedih dan pilu kerana manusia tidak pernah bersyukur pada-NYA tentang segala perbekalan dan perlengkapan ini. Memang manusia menzalimi perlengkapan di dalam dan pada dirinya dan terus menzalimi perbekalan di alam semesta di luar dirinya. Dan kemudian menzalimkan petunjuk, iaitu al-Quran dan al-sunnah yang diwahyukan kepada rasul kesayangan-NYA. Sesungguhnya manusia itu sangat ingkar dan tidak berterima kasih kepada TUHAN-nya (1006:6). Sesungguhnya, manusia itu sangat cinta kepada harta (100:8).

(Shahnon, 2011:15-16)

Selain itu, pengarang turut menampilkan kehebatan dan kebesaran Allah SWT dengan mengemuka beberapa ayat lain, iaitu Surah an-Nisa' ayat $32^{5}$, $34^{6}$ dan $35^{7}$. Tujuannya adalah untuk meyakinkan khalayak pembaca bahawa Allah sebagai Tuhan yang bersifat kamal (sempurna) mengatasi kehebatan dan kebesaran manusia. Malahan menerusi Surah al-Ahzab, ayat $4^{8}$ juga turut menunjukkan bahawa kesempurnaan Allah sebagai petunjuk jalan yang benar kepada manusia, dan seharusnya manusia mengikut jalan yang ditunjuk itu demi kemaslahatan sejagat. Perihal sedemikian dinyatakan pengarang seperti contoh di bawah:

ALLAH Maha Mengetahui dengan segala sesuatu (4:32). ALLAH Maha Tinggi lagi Maha Besar (4:34). ALLAH Maha Mengetahui dan amat mendalam ilmu-Nya (4:35). ALLAH menyatakan yang benar dan DIAlah yang menunjukkan jalan yang benar (33:4).

Dan ALLAH tidak jemu-jemu berpesan: Tidak ada TUHAN selain aku, maka sembahlah AKU dan dirikanlah solat untuk mengingati-KU(20:14).

(Shahnon, 2011:29-30) 
Penelitian terhadap kesempurnaan Allah bukan sekadar terhadap keagungannya mencipta manusia, bahkan kehebatannya mencipta alam semesta. Maka, hal ini diungkapkan pengarang dalam Revolusi yang Ditangguhkan. Karya ini mengemukakan kesempurnaan Allah sebagai pencipta alam semesta yang menciptakan langit, matahari, hujan dan tumbuhan. Hal ini sebagaimana tercatat dalam al-Quran menerusi beberapa surah, antaranya Surah an-Naba, ayat 6-169. Maka, diajukan contoh yang diungkapkan pengarang seperti yang berikut:

Bukankah ALLAH bina tujuh lapis langit yang serba kukuh? Bukankah ALLAH ciptakan mentari yang amat terang? Bukankah ALLAH turunkan hujan yang tercurah-curah? Bukankah ALLAH tumbuhkan dengan hujan itu biji-bijian, tumbuh-tumbuhan dan kebun-kebun yang lebat? (78:6-16)

(Shahnon, 2011:31)

Selain itu, garapan tentang kesempurnaan Allah turut diketengahkan pengarang dalam Revolusi yang Ditangguhkan dengan penyataan bahawa kekuasaan menghidupkan dan mematikan semua benda di atas muka bumi ini. Kesempurnaan Allah SWT yang menghidupkan dan mematikan semua benda ini banyak dinyatakan dalam al-Quran menerusi banyak surah yang perlu dihayati oleh manusia sebagai iktibar. Malahan, dengan penghayatan terhadap asmaul-Husna turut menyerlahkan kesempurnaan Allah SWT sebagai Tuhan Yang Maha Berkuasa. Maka, hal ini dinyatakan pengarang dalam contoh berikut:

Sememangnya, DIAlah yang berhak memusnahkan segalanya dengan sekelip mata tanpa sebarang muslihat dan DIA pula dengan sekelip mata melahirkan kaum lain yang baru dan yang dikehendaki-NYA. DIAlah yang berhak melahirkan sesuatu. DIA jugalah yang menguruskan sesuatu. Dan DIA juga yang mematikan sesuatu untuk kelak menghidupkan semula yang dimatikan-NYA.

(Shahnon, 2011:183)

\section{Prinsip Kerasulan sebagai Insan Kamil (Sempurna)}

Berdasarkan Revolusi yang Ditangguhkan, prinsip kerasulan sebagai insan kamil dikemukakan Shahnon menerusi petunjuk yang diberikan Allah SWT kepada rasul untuk keamanan dan kesejahteraan umat manusia. Hal ini ditampilkan pengarang tentang keistimewaan rasul sebagai utusan Allah 
SWT untuk menyampaikan kebenaran dalam Islam, berserta petunjuk yang digariskan dalam agama agar dipatuhi umat manusia. Oleh itu, perihal kerasulan sebagai utusan Allah SWT yang bersifat kamil ini digambarkan Shahnon seperti contoh yang berikut:

Begitu banyak petunjuk daripada-NYA dan disertai pula oleh para rasul yang menyampaikan petunjuk-petunjuk itu kepada manusia dari zaman ke zaman demi kesejahteraannya di dunia mahupun di akhirat.

(Shahnon, 2011:30)

Selain itu, garapan tentang prinsip kerasulan sebagai insan kamil dinyatakan pengarang dalam Revolusi yang Ditangguhkan berdasar sahsiah nabi sebagai utusan yang banyak menyalurkan nasihat dan peringatan yang berguna kepada umat manusia. Keperibadian Rasulullah SAW sebagai utusan yang banyak memberikan peringatan tercatat dalam banyak surah, antaranya termasuklah Surah al-Imran, ayat 3-4 ${ }^{10}$, Surah al-Bayyinah ayat $1-5^{11}$. Maka, hal ini diketengahkan pengarang seperti contoh berikut:

Bukankah al-Quran itu adalah kitab suci yang membenarkan kitab-kitab suci lain yang sebelumnya; malah sebagai ujian bagi kitab-kitab tersebut? (3:34). Dengan itu Muhammad memberi peringatan dan nasihat kepada semua manusia dan menjelaskan apa yang mereka selisihkan serta memberi rahmat dan petunjuk bagi orang yang bertakwa (98:1-5) merupakan peringatan bagi mereka yang lalai.

(Shahnon, 2011:61)

Prinsip kerasulan sebagai insan kamil turut diperikan pengarang dalam Revolusi yang Ditangguhkan berdasarkan sahsiah mulia nabi sebagai utusan untuk umat manusia. Hal ini diketengahkan Shahnon menerusi beberapa ujaran ayat al-Quran, misalnya dalam Surah an-Najm ayat 1-4 ${ }^{12}$, Surah al-Ahzab ayat $21^{13}$ dan Surah al-Baqarah ayat $85^{14}$. Surah terbabit memperihalkan tentang keperibadian Rasulullah SAW sebagai qudwah-hasanah (contohteladan) dalam menampilkan akhlak mulia, yang menjadi contoh dan ikutan manusia di muka bumi. Maka, gambaran tersebut dapat dilihat dalam Revolusi yang Ditangguhkan seperti contoh di bawah:

Demikian juga apa yang diucap atau yang didiamkan oleh Rasulullah. Segala perlakuannya adalah bukan daripada tuntutan hawa nafsu tapi adalah 
daripada-NYA (53:1-4). Rasulullah adalah teladan paling baik bagi manusia yang mengharapkan rahmat ILAHI (33:21) Dan manusia yang mengingkari sunah rasul pada dasarnya hanya beriman kepada sebahagian ayat al-Quran dan mengingkari sebahagian lainnya (2:85). Dan kami tidak akan mengutus seorang rasul melainkan untuk ditaati dengan seizin ALLAH (4:64)

(Shahnon, 2011:63)

\section{Prinsip Keislaman yang Bersifat Akmal (Sempurna)}

Prinsip keislaman yang bersifat akmal (sempurna) dikemukakan pengarang dalam Revolusi yang Ditangguhkan berdasarkan peri pentingnya al-Quran terhadap umat manusia di muka bumi ini. Malah, sejajar dengan prinsip Islam bahawa al-Quran merupakan rujukan utama kepada umat Islam bagi merealisasikan kehidupan yang sejahtera dan harmoni. Didapati bahawa al-Quran dijadikan sebagai panduan dan pedoman umat Islam bagi semua aspek kehidupan. Maka ini termaktub dalam banyak surah dalam al-Quran, misalnya Surah at-Takwir ayat 25-2715, Surah al-Maidah ayat $16^{16}$, Surah al-Kahfi ayat 1-2 $2^{17}$ dan Surah Ibrahim ayat $52^{18}$. Justeru, hal ini disuguhkan pengarang sebagaimana contoh di bawah:

Al-Quran itu tidak lain hanyalah peringatan bagi semesta alam (81:25-27). DIA membawa cahaya terang benderang untuk mengeluarkan manusia daripada kegelapan, memberi penjelasan dan bimbingan yang lurus $(5: 16)$ sebagai berita gembira bagi yang beriman dan beramal soleh (18:1-2). Dan memberi petunjuk kepada yang dikehendaki-NYA, iaitu bagi mereka yang mahu mengambil pelajaran daripadanya (14:52).

(Shahnon, 2011:61)

Menerusi Revolusi yang Ditangguhkan juga terserlah prinsip Islam yang bersifat akmal ditampilkan pengarang tentang al-Quran yang menitikberatkan pelbagai petunjuk dan amanat untuk seluruh manusia. Peri pentingnya Islam sebagai agama yang sempurna telah dijelaskan dalam banyak surah yang menunjukkan kesyumulannya yang meliputi semua aspek kehidupan manusia. Misalnya dalam urusan ibadah, dakwah, ekonomi, sosial, dan perundangan yang menunjukkan Islam merupakan agama yang sempurna. Pengarang telah mengemukakannya dalam karya seperti yang berikut:

Di samping perlengkapan dan perbekalan itu, diberinya pula petunjuk dan pemimpin yang terdiri daripada kitab yang sahih daripada-NYA, yang berakhir 
dengan kitab suci al-Quran yang dijamin oleh-NYA tentang kesahihannya. Juga, sejak mula berfungsi sebagai penyampai wahyu dan pemimpin itu tamat dengan Muhammad SAW.

(Shahnon, 2011:93)

Didapati bahawa agama Islam menekankan ganjaran pahala dan dosa. Berdasarkan al-Quran menunjukkan timbangan dosa dan pahala manusia bergantung pada perbuatan baik dan jahat. Hal ini termaktub dalam Surah az-Zalzalah ayat 1-8. ${ }^{19}$ Maka, pengarang menampilkan surah tersebut bagi menunjukkan prinsip Islam yang bersifat akmal sejajar dengan prinsip dalam teori takmilah sebagaimana contoh berikut:

Barang siapa yang mengerjakan kebaikan seberat zarah pun, nescaya akan melihat balasannya. Dan barang siapa yang mengerjakan kejahatan seberat zarah pun, nescaya akan melihat balasannya (99:1-8)

(Shahnon, 2011:218)

\section{Prinsip Ilmu dengan Sastera yang Bersifat Takmilah (Sempurna)}

Prinsip ilmu dengan sastera yang bersifat takmilah (sempurna) dalam Revolusi yang Ditangguhkan terserlah menerusi garapan pengarang mempertalikan ilmu sains, sastera dengan konteks Islam. Hal ini berdasarkan peri pentingnya manusia menyedari tentang kewujudan makhluk yang lain seperti langit, bintang, matahari, bulan, pokok-pokok dan gunung-ganang. Berdasarkan ilmu sains, jelas perihal peredaran bumi diperkatakan dengan fakta yang bersesuaian. Walhal dalam Islam juga fenomena kosmologi disebutkan dalam al-Quran menerusi surah tertentu untuk menunjukkan kehebatan dan kebesaran Yang Maha Pencipta, iaitu Allah SWT. Maka, pengarang mengetengahkan gabungan ilmu sains dan Islam dengan gubahan gaya bahasa sastera yang difahami pembaca. Hal ini untuk menyerlahkan kehebatan ilmu milik Allah SWT untuk kemaslahatan umat jagat raya. Contoh di bawah memperlihatkan cara pengarang mengutarakan prinsip terbabit:

Oleh itu, DIA menghiasi langit dengan bintang dengan gugusan serta sinarnya yang serba lunak. Bintang-bintang sering pula beredar dan kemudian beradu. Dan langit mempunyai garis edar bintang-bintang dan planet-planet. Matahari dan bulan juga beredar pada orbitnya. Dan matahari bersinar. Dan bulan 
bercahaya. Begitu juga bumi dihiasi dengan pokok-pokok, gunung-ganang, sungai yang berliku dan berlubuk.

(Shahnon, 2011:50)

\section{Prinsip Sastera yang Berciri Estetik dan Bersifat Takmilah (Sempurna dan Menyempurnakan)}

Prinsip sastera yang bercirikan estetik dan bersifat takmilah (sempurna dan menyempurnakan) dikemukakan pengarang dalam Revolusi yang Ditangguhkan berdasarkan gaya bahasa yang memikat pembaca. Dalam konteks ini pengarang menampilkan diksi dan imej yang berusaha mendidik pembaca dengan bahasa yang berhemah dan menyentuh perasaan. Perkataan seperti "guntur dan kilat mulai naik radang" membawa mesej kealpaan manusia kepada agama dan Islam akan menyebabkan alam turut berdukacita. Justeru, penggunaan perkataan "radang" yang sifatnya untuk manusia, diacukan kepada "guntur" dan "kilat" memperlihatkan sastera sendiri yang berciri estetik dan bersifat sempurna dan menyempurnakan dalam mengajak manusia bermuhasabah dalam kehidupan. Oleh yang demikian, contoh dapat ditampilkan seperti di bawah:

Biasanya begitulah juga bila guntur dan kilat mulai naik radang dan awan berarak bergumpalan dengan segala kehitaman bendungannya. Tapi kali ini, di mana-mana di langit dan angkasa, suasananya ternyata terkawal. Penuh keindahan, penuh keharmonian, tetap syahdu dengan aliran yang serba tertib beradab dengan kejernihan dan kebugarannya bagaikan ditapis lebih awal dengan jaringan yang terpilih, menghakiskan segala sampah sarap, lumut dan para sisa beraneka.

(Shahnon, 2011:80)

Revolusi yang Ditangguhkan turut mengemukakan prinsip sastera sendiri yang berciri estetik dan bersifat takmilah (sempurna dan menyempurnakan) berdasarkan penggunaan rangkai kata "perdu gunung", "urat saraf bumi", "membelai setiap lekuk", "rianglah para cacing" dan "menjilat sisa yang tebal" yang menumbuhkan kesegaran dalam pembacaan. Didapati setiap rangkai kata sifat manusia yang diadunkan dengan alam memperlihatkan keindahan yang tersendiri yang mengajak manusia merenung dan berfikir tentang kehebatan dan keagungan Allah SWT sebagai Yang Maha Pencipta. Kejadian alam yang dinukilkan dengan gaya bahasa yang berhikmah 
menunjukkan prinsip sastera yang berciri estetik dan bersifat takmilah. Justeru, hal ini dapat diperhatikan menerusi contoh di bawah:

Bintil-bintil air yang terpancut dari kaki bukit dan perdu gunung akan meresap seperti cahaya juga, memasuki urat saraf bumi dan menusuk sambil membelai setiap lekuk dan lurah di bumi. Akan rianglah para cacing serta bergelutlah mereka menggemburkan bumi untuk dijadikan persediaan makhluk baru. Mereka terus menguli ketulan bumi yang keras menjadi lembut dan sekali gus menjilat sisa yang tebal melekat pada akar-akar dan batu-batunya.

(Shahnon, 2011:168)

\section{Prinsip Pengkarya Mengistikmalkan Diri (Menyempurnakan)}

Berdasarkan Revolusi yang Ditangguhkan, pengarang mengemukakan prinsip kepada pengkarya yang seharusnya mengistikmalkan diri (menyempurnakan) dalam proses menghasilkan karya. Didapati menerusi Revolusi yang Ditangguhkan, hal ini terserlah. Pengarang melahirkan rasa penghambaannya sebagai manusia yang serba lemah lantaran penyakit yang dita nggung hanya mengharapkan keredhaan Allah SWT agar memberikan petunjuk dan ilham untuk berkarya dengan lancar. Pergantungan pengarang terhadap Allah SWT selain usaha kerasnya bergelumang dengan bahan agama untuk menghasilkan sebuah penulisan berbentuk rohani, maka telah merungkai permasalahan yang membelenggu dirinya. Pengarang berusaha membentuk keimanan dan ketakwaan pada dirinya untuk menghasilkan karya yang terbaik untuk khalayak. Perihal ini ditunjukkan pengarang berdasarkan contoh penyataan di bawah:

Maka pelbagailah kegusaran melanda. Bagaimana boleh aku memperolehi ilham dalam keadaan sedaif begini? Namun, sebagai seorang hamba, aku tetap yakin bahawa dengan kuasa-NYA, segala kebimbangan akan terlerai jua.

(Shahnon, 2011:9)

\section{Prinsip Khalayak ke Arah Insan Kamil (Sempurna)}

Prinsip khalayak bertujuan memupuk mereka ke arah insan kamil (sempurna) turut diketengahkan pengarang dalam Revolusi yang Ditangguhkan. Menerusi buku ini, pengarang menampilkan banyak unsur pengajaran untuk khalayak bermuhasabah dan berfikir tentang kehebatan dan kebesaran Allah SWT. Pengarang mengajak pembaca merenung tentang kejadian alam semesta dengan 
mempertalikannya dengan kehidupan manusia. Didapati bahawa pengarang mengajak pembaca sentiasa mengelakkan diri daripada keangkuhan diri untuk menjadi manusia yang menuju ke arah kesempurnaan dalam kehidupan. Pengarang mengajak manusia sentiasa mendekatkan diri dengan agama agar tidak terpesong ketika berhadapan dengan cabaran hidup yang penuh dugaan. Hal ini telah digarap pengarang seperti contoh berikut:

Gunung-ganang. Bukit bukau. Rimba belantara. Langit. Bumi. Lautan. Angkasa. Angin. Binatang. Air dari bumi. Air hujan dari langit. Pokok-pokok dan tumbuh-tumbuhan. Matahari. Bulan. Bintang. Planet yang dapat dilihat dan yang ghaib. Burung-burung. Semuanya adalah makluk-NYA yang kini sedang memerhatikan gelagat dan kesombongan manusia terhadap ALLAH dan rasul-NYA dan juga terhadap diri mereka sendiri.

(Shahnon, 2011:69)

Selain itu, berdasarkan Revolusi yang Ditangguhkan memperlihatkan prinsip khalayak bertujuan memupuk mereka ke arah insan kamil (sempurna) menerusi rasa keinsafan pembaca terhadap hari kiamat. Pengarang menyeru pembaca agar sentiasa bersiap siaga menempuh hari pembalasan yang telah ditetapkan Allah SWT. Hal ini telah disuguhkan oleh pengarang seperti contoh berikut:

Dunia sudah terlalu tua untuk menampungi kediaman mereka dan sudah sampai ketikanya supaya mereka semua dihapuskan. Hari pembinasaan akan tiba segera supaya mereka yang derhaka akan menerima balasan yang setimpal bila hisab dan kelak bermula di kala kebangkitan semula.

(Shahnon, 2011:204)

Pengarang menyeru manusia agar mempersiapkan diri menjadi insan Kamil dan sentiasa patuh pada perintah-Nya.

\section{KESIMPULAN}

Berdasarkan tujuh prinsip yang digariskan dalam teori takmilah jelas dikemukakan pengarang dalam Revolusi yang Ditangguhkan. Hal ini dapat diperhatikan menerusi gambaran pengarang dalam setiap bab yang digarap. Pengarang berusaha mengajak khalayak menjalinkan hubungan manusia dengan Allah SWT (habl min Allah) dan hubungan manusia dengan manusia (habl min al-Nas). Berdasarkan penggaluran tujuh prinsip dalam perspektif 
takmilah, didapati prinsip keenam, iaitu prinsip pada pengkarya yang seharusnya mengistikmalkan diri (menyempurnakan) dan ketujuh, iaitu prinsip khalayak bertujuan memupuk mereka ke arah insan kamil (sempurna) jelas diketengahkan pengarang dalam buku ini sebagai karya bersifat rohani.

Pengarang, dalam usianya yang telah mencecah warga emas, sekali gus ditimpa penyakit, begitu tekal berusaha mendidik hati pembaca untuk merenung, berfikir dan bermuhasabah tentang kehidupan yang sarat dengan dugaan. Karya ini mengajak pembaca berusaha menyempurnakan diri menjadi manusia yang patuh pada suruhan-Nya dan menjauhi larangan-Nya. Selain itu, karya ini mengingatkan manusia tentang kehebatan dan keperkasaan Allah SWT sebagai Yang Maha Pencipta di samping Rasulullah SAW sebagai utusan dan qudwah hasanah serta menjadikan al-Quran sebagai pedoman. Maka, dengan garapan bahasa dan gaya bahasa yang indah berserta dengan ilmu sastera yang dimiliki pengarang menjadikan Revolusi yang Ditangguhkan bukan sekadar untuk sasaran golongan tertentu, atau peringkat usia yang ditetapkan bahkan untuk semua pembaca tanpa mengenal sempadan dan zaman. Karya ini seharusnya dimanfaatkan oleh setiap lapisan masyarakat demi kemaslahatan umat jagat raya.

\section{NOTA}

1. Penjelasan lanjut tentang sejarah teori takmilah, sila lihat Kamariah Kamarudin, 2011. Takmilah dalam Novel Melayu. Kuala Lumpur: Dewan Bahasa dan Pustaka, hlm. 74114.

2. Maklumat lanjut tentang penambahbaikan teori takmilah telah diajukan oleh penjana teori, sila rujuk Shafie Abu Bakar, 2014. "Gagasan Pesurat Pelengkap Takmilah: Bangi Makmal Menyerlah" dlm. Teori Takmilah - Perluasan dan Penafsiran. Selenggaraan Abdul Halim Ali. Tanjung Malim: Persatuan Penulis Budiman Malaysia, hlm. 11-21.

3. Sila lihat Shahnon Ahmad, 2006. Perjalananku Sejauh Ini: Sebuah Autobiografi. Gelugor: Pustaka shahnonahmad, hlm. 192-93.

4. Terjemahan yang bermaksud: "Dan berilah perumpamaan kepada mereka (manusia), kehidupan dunia adalah sebagai air hujan yang Kami turunkan dari langit, maka menjadi subur kerananya tumbuh-tumbuhan di muka bumi, kemudian tumbuh-tumbuhan itu menjadi kering yang diterbangkan oleh angin. Dan adalah Allah Maha Berkuasa atas segala sesuatu, hlm. 450 .

5. Dan janganlah kamu iri hati terhadap apa yang dikurniakan Allah kepada sebahagian kamu lebih banyak dari sebahagian yang lain (kerana) bagi orang laki-laki ada bahagian daripada apa-apa yang mereka usahakan, dan bagi para wanita (pun) ada bahagian daripada apa-apa yang mereka usahakan, dan mohonlah kepada Allah sebahagian daripada kurnia-Nya. Sesungguhnya Allah Maha Mengetahui segala sesuatu, hlm. 122.

6. Kaum laki-laki itu ialah pemimpin bagi kaum wanita, oleh kerana Allah telah melebihkan sebahagian mereka (laki-laki) atas sebahagian yang lain (wanita), dan kerana mereka 
(laki-laki) telah menafkahkan sebahagian dari harta mereka. Sebab itu maka wanita yang saleh, ialah yang taat kepada Allah lagi memelihara diri ketika suaminya tidak ada, oleh sebab Allah telah memelihara mereka. Wanita-wanita yang kamu khuatirkan nusyuznya, maka nasihatilah mereka dan pisahkanlah mereka di tempat tidur mereka, dan pukullah mereka. Kemudian jika mereka mentaatimu, maka janganlah kamu mencari-cari jalan untuk menyusahkannya. Sesungguhnya Allah Maha Tinggi lagi Maha Besar, hlm. 123.

7. Dan jika kamu khuatirkan ada persengketaan antara keduanya, maka kirimlah seorang hakam daripada keluarga laki-laki dan seorang hakam daripada keluarga perempuan. Jika kedua orang hakam itu bermaksud mengadakan perbaikan, nescaya Allah memberikan taufik kepada suami isteri itu. Sesungguhnya Allah Maha Mengetahui lagi Maha Mengenal, hlm. 123.

8. Allah sekali-kali tidak menjadikan bagi seseorang dua hati dalam ronggannya; dan Dia tidak menjadikan isteri-isterimu yang kamu zihar itu sebagai ibumu, dan Dia tidak menjadikan anak-anak angkatmu sebagai anak kandunganmu (sendiri). Yang demikian itu hanyalah perkataanmu di mulutmu saja. Dan Allah mengatakan yang sebenarnya Dia menunjukkan jalan (yang benar), hlm. 666.

9. Bukankah Kami telah menjadikan bumi itu sebagai hamparan? Dan gunung-gunung sebagai pasak? Dan Kami jadikan kamu berpasang-pasangan, dan Kami jadikan tidurmu untuk istirahat, dan Kami jadikan malam sebagai pakaian, dan Kami jadikan siang untuk mencari penghidupan, dan Kami bangunkan di atas kamu tujuh (langit) yang kukuh, dan Kami turunkan dari awan air yang banyak tercurah, supaya Kami tumbuhkan dengan air itu biji-bijian dan tumbuh-tumbuhan, dan kebun-kebun yang lebat?” (hlm. 1014-015).

10 "Dia menurunkan al-Kitab (al-Quran) kepadamu dengan sebenarnya; membenarkan kitab yang telah diturunkan sebelumnya dan menurunkan Taurat dan Injil sebelum alQuran menjadi petunjuk bagi manusia, dan Dia menurunkan al-Furqan. Sesungguhnya orang-orang yang kafir terhadap ayat-ayat Allah akan memperoleh seksa yang berat; dan Allah Maha Perkasa lagi mempunyai balasan (seksa)", hlm. 75.

11 Orang-orang kafir yakni ahli kitab dan orang-orang musyrik (mengatakan bahawa mereka) tidak akan meninggalkan (agamanya) sebelum datang kepada mereka bukti yang nyata, iaitu seorang Rasul daripada Allah (Muhammad) yang membacakan lembaranlembaran yang disucikan (al-Quran), di dalamnya terdapat isi kitab-kitab yang lurus. Dan tidaklah berpecah belah orang-orang yang didatangkan al-Kitab kepada mereka melainkan sesudah datang kepada mereka bukti yang nyata. Padahal mereka tidak disuruh kecuali supaya menyembah Allah dengan memurnikan ketaatan kepada-Nya dalam menjalankan agama dengan lurus, dan supaya mereka mendirikan solat dan menunaikan zakat; dan yang demikian itulah agama yang lurus”, hlm. 1084.

12 "Demi bintang ketika terbenam, kawanmu Muhammad tidak sesat dan tidak pula keliru, dan tiadalah yang diucapkannya itu (al-Quran) menurut kemahuan hawa nafsunya. Ucapannya itu tiada lain hanyalah wahyu yang diwahyukan kepadanya", hlm. 871.

13 "Sesungguhnya telah ada pada (diri) Rasulullah itu suri teladan yang baik bagimu, iaitu bagi orang yang mengharap (rahmat) Allah dan (kedatangan) hari kiamat dan dia banyak menyebut Allah", hlm. 670.

14 Kemudian kamu (Bani Israil) membunuh dirimu (saudaramu sebangsa) dan mengusir segolongan daripada kamu dari kampung halamannya, kamu bantu-membantu terhadap mereka dengan membuat dosa dan permusuhan; tetapi jika mereka datang kepadamu sebagai tawanan, kamu tebus mereka, padahal mengusir mereka itu (juga) terlarang 


\section{MALAY LITERATURE VOLUME 29 NUMBER 2 DECEMBER 2016}

bagimu. Apakah kamu beriman kepada sebahagian al-Kitab (Taurat) dan ingkar terhadap sebahagian yang lain? Tiadalah balasan bagi orang yang berbuat demikian daripadamu, melainkan kenistaan dalam kehidupan dunia, dan pada hari kiamat mereka dikembalikan kepada seksa yang sangat berat. Allah tidak lengah daripada apa yang kamu perbuat", hlm. 24.

15 "Dan al-Quran itu bukanlah perkataan syaitan yang terkutuk, maka ke manakah kamu akan pergi? Al-Quran itu tiada lain hanyalah peringatan bagi semesta alam”, hlm. 1029.

16 "Dengan kitab itulah Allah menunjuki orang-orang yang mengikuti keredaan-Nya ke jalan keselamatan, dan (dengan kitab itu pula) Allah mengeluarkan orang-orang itu daripada gelap gelita kepada cahaya yang terang benderang dengan seizin-Nya, dan menunjuki mereka ke jalan yang lurus", hlm. 161.

17 "Segala puji bagi Allah yang telah menurunkan kepada hamba-Nya al-Kitab (al-Quran) dan Dia tidak mengadakan kebengkokan di dalamnya; sebagai bimbingan yang lurus, untuk memperingatkan akan seksaan yang sangat pedih dari sisi Allah dan memberi berita gembira kepada orang-orang yang beriman, yang mengerjakan amal saleh, bahwa mereka akan mendapat pembalasan yang baik", hlm. 443 .

18 Al-Quran ini ialah penjelasan yang sempurna bagi manusia, dan supaya mereka diberikan peringatan dengannya, dan supaya mereka mengetahui bahwasanya Dia adalah Tuhan Yang Maha Esa dan agar orang-orang yang berakal mengambil pelajaran”, hlm. 368.

19 "Apabila bumi digoncangkan dengan goncangannya yang dahsyat, dan bumi telah mengeluarkan beban-beban berat (yang dikandungnya), dan manusia bertanya: "Mengapa bumi (jadi begini)?", pada hari itu bumi menceritakan beritanya, kerana sesungguhnya Tuhanmu telah memerintahkan (yang demikian itu) kepadanya. Pada hari itu manusia keluar dari kuburnya dalam keadaan yang bermacam-macam, supaya diperlihatkan kepada mereka (balasan) pekerjaan mereka. Sesiapa yang mengerjakan kebaikan seberat zarah pun, nescaya dia akan melihat (balasannya). Dan sesiapa yang mengerjakan kejahatan seberat zarah pun, nescaya dia akan melihat (balasannya) pula", hlm. 1087.

\section{RUJUKAN}

Abdul Halim Ali (peny.), 2014. Teori Takmilah Perluasan dan Penafsiran. Tanjung Malim: Persatuan Penulis Budiman Malaysia.

Kamariah Kamarudin, 2011. Takmilah dalam Novel Melayu. Kuala Lumpur: Dewan Bahasa dan Pustaka.

Mohd. Yusof Hasan , 1975/76. “Bahasa Daerah dalam Karya-karya Shahnon Ahmad". Tesis M.A. Pusat Pengajian ilmu Kemanusiaan, USM, P.Pinang.

Mohammad Yusof Hasan, 1972. Kajian dan Pembicaraan Novel Rentong. Dinas Penerbitan Pustaka Sekolah.

Muhammad Noor Haji Ibrahim, Abdullah Basmeh, 2010. Tafsir Pimpinan ar-Rahman kepada Pengertian al-Qur'an (30 Juzuk). Kuala Lumpur: Darul Fikir.

Ooi Eng Lye, 1996, 1996. "Novel-novel Mutakhir Shahnon Ahmad (1980-an-1990an): Satu Kajian Perhubungan Gender". Tesis M.A., Pusat Pengajian Ilmu Kemanusiaan, USM.

Shafie Abu Bakar, 2014. “Gagasan Pesurat Pelengkap Takmilah: Bangi Makmal 
Menyerlah" dlm. Teori Takmilah - Perluasan dan Penafsiran. Diselenggara oleh Abdul Halim Ali. Tanjung Malim: Persatuan Penulis Budiman Malaysia. Shahnon Ahmad, 2006. Perjalananku Sejauh Ini: Sebuah Autobiografi. Gelugor: Pustaka Shahnonahmad.

Shahnon Ahmad, 2011. Revolusi yang Ditangguhkan. Shah Alam: Karangkraf Sdn. Bhd.

Shahnon Ahmad, 1978. Penglibatan dalam Puisi . Kuala Lumpur: Utusan Melayu Publication.

Shahnon Ahmad, 1979. Gubahan Novel. Kuala Lumpur: Dewan Bahasa dan Pustaka. Shahnon Ahmad, 1981. Kesusasteraan dan Etika Islam. Shah Alam: Fajar Bakti.

Shahnon Ahmad, 1987. Polemik Sastera Islam. Kuala Lumpur: Dewan Bahasa dan Pustaka.

Shahnon Ahmad, 1991. Seni Sastera Sebagai Seismograf Kehidupan. Kuala Lumpur: Dewan Bahasa dan Pustaka.

Shahnon Ahmad, 1992. Kesasterawanan: Kepolitikan, Kealaman, Kedirian, Kemanusiaan. Kuala Lumpur: Dewan Bahasa dan Pustaka.

Shahnon Ahmad, 1993. Pongang Sastera. Shah Alam: Fajar Bakti.

Shahnon Ahmad, 1995. Corat-corat Berkelongsong. Shah Alam: Fajar Bakti.

Shahnon Ahmad, 1994. Sastera: Pengalaman, Ilmu, Imaginasi dan Kitarannya. Kuala Lumpur: Dewan Bahasa dan Pustaka.

Sohaimi Abdul Aziz, 1990/91. "Mobiliti Sosial Perspektif Barat dan Islam dalam Novel-novel Terpilih Shahnon Ahmad." Latihan Ilmiah, Pusat Pengajian Ilmu Kemanusiaan, USM.

Talib Samat, 2006. Teknik NaratifCerpen-cerpen Shahnon Ahmad. Tanjong Malim, Perak : Penerbitan UPSI.

Ungku Maimunah Mohd Tahir, 1998. Antara Kampung dan Kota: Rural Bias in The Novels of Shahnon Ahmad. Cetakan 1. Bangi: Penerbit Universiti Kebangsaan Malaysia.

Received: 22 April 2016

Accepted: 21 November 2016 